University of Nebraska - Lincoln

DigitalCommons@University of Nebraska - Lincoln

Faculty Publications: Department of Entomology

Entomology, Department of

2012

\title{
Using Web-Based Key Character and Classification Instruction for Teaching Undergraduate Students Insect Identification
}

Douglas A. Golick

University of Nebraska-Lincoln, dgolick2@unl.edu

Tiffany M. Heng-Moss

University of Nebraska-Lincoln, thengmoss2@unl.edu

Allen L. Steckelberg

University of Nebraska-Lincoln, asteckelberg1@unl.edu

David W. Brooks

University of Nebraska-Lincoln, dbrooksne@gmail.com

Leon G. Higley

University of Nebraska-Lincoln, Ihigley1@unl.edu

See next page for additional authors

Follow this and additional works at: https://digitalcommons.unl.edu/entomologyfacpub

Part of the Curriculum and Instruction Commons, Educational Methods Commons, Entomology

Commons, Higher Education Commons, Higher Education and Teaching Commons, Instructional Media

Design Commons, and the Science and Mathematics Education Commons

Golick, Douglas A.; Heng-Moss, Tiffany M.; Steckelberg, Allen L.; Brooks, David W.; Higley, Leon G.; and Fowler, David, "Using Web-Based Key Character and Classification Instruction for Teaching Undergraduate Students Insect Identification" (2012). Faculty Publications: Department of Entomology. 352.

https://digitalcommons.unl.edu/entomologyfacpub/352

This Article is brought to you for free and open access by the Entomology, Department of at DigitalCommons@University of Nebraska - Lincoln. It has been accepted for inclusion in Faculty Publications: Department of Entomology by an authorized administrator of DigitalCommons@University of Nebraska - Lincoln. 


\section{Authors}

Douglas A. Golick, Tiffany M. Heng-Moss, Allen L. Steckelberg, David W. Brooks, Leon G. Higley, and David Fowler 
Published in the Journal of Science Education and Technology (2013) 22: 509-521. DOI: 10.1007/s10956-012-9410-z. Copyright 2013, Springer. Used by permission.

\title{
Using Web-Based Key Character and Classification Instruction for Teaching Undergraduate Students Insect Identification
}

\author{
Douglas A. Golick, Tiffany M. Heng-Moss, Allen L. Steckelberg, David. W. Brooks, Leon G. \\ Higley, David Fowler
}

\section{Abstract}

The purpose of the study was to determine whether undergraduate students receiving web-based instruction based on traditional, key character, or classification instruction differed in their performance of insect identification tasks. All groups showed a significant improvement in insect identifications on pre-and posttwo-dimensional picture specimen quizzes. The study also determined student performance on insect identification tasks was not as good as for family-level identification as compared to broader insect orders and arthropod classification identification tasks. Finally, students erred significantly more by misidentification than misspelling specimen names on prepared specimen quizzes. Results of this study support that short web-based insect identification exercises can improve insect identification performance. Also included is a discussion of how these results can be used in teaching and future research on biological identification.

Keywords: Insect identification, Entomology, Webbased instruction, Classification, Key character

D. A. Golick (corresponding author; dgolick2@unl.edu), T. M. HengMoss, Department of Entomology, University of Nebraska-Lincoln, Lincoln, Nebraska, USA

A. L. Steckelberg, David. W. Brooks, D. Fowler, Teaching, Learning, and Teacher Education, University of Nebraska-Lincoln, Lincoln, Nebraska, USA

L. G. Higley, School of Natural Resources, University of NebraskaLincoln, Lincoln, Nebraska, USA

Published online: August 30, 2012
Introduction

Insects impact virtually every aspect of human society. They are valuable pollinators of plants, are food for both vertebrates and invertebrates, recycle nutrients, aerate soil, and provide commercial products such as beeswax, honey, and silk. Insects are also vectors of many diseases. As a result, insects affect many industries and professions throughout the world. In addition to the understanding of insect biology, physiology, and ecology, the ability to efficiently and correctly identify insect specimens is crucial to the function of these industries and professions. People in agricultural professions must be able to identify insects for proper diagnosis of pest damage and to accurately determine which control measures are appropriate. Ecologists need to identify aquatic insects to make recommendations about the quality of water in a stream. The ability to identify insects is especially important for criminal forensic entomologists in determining the time and vicinity of death.

Professionals that practice insect identification likely receive training presented either through extension educators, traditional classroom instruction, worksite training, or through distance learning technologies. Common instructional techniques utilized in formal settings include examination of prepared specimens (preserved specimens), presentation of key morphological characters of insect taxa, use of dichotomous keys, and student identification practice with prepared or pictorial specimens (Dunn 1994; Johnson and Triplehorn 2005). In addition, other approaches such 
as instructor supervised field excursions and student prepared insect collections are commonly used for teaching insect identification.

An aspect of formal insect identification instruction is the examination of prepared specimens (specimens pinned, suspended in alcohol medium, or slide mounted). The use of prepared specimens is widely recognized as an important part of teaching insect identification (Dunn 1994). Prepared specimens provide students practice in observing the key characters of a taxon, general appearance, and the variety of forms in a taxon. In a given class, students may be shown one or several examples of specimens belonging to a taxon, especially those common locally. Providing students with many examples of insects belonging to a group is important in teaching insect identification so they appreciate the diversity that exists among insects.

Sight identification is a goal of many introductory entomology courses. Sight identification is the ability to identify or name an insect to a taxon using memory only, without the use of dichotomous keys, field guides, or expert assistance. Sight identification is different from other means of identification in that it relies on memory to correctly name a specimen to the correct classification taxa.

To examine how students identify insects, it is necessary to discuss the theoretical perspectives on human object identification. In general, human object identification theories address either the recognition or categorization steps in the object identification process (Schyns 1998). Human object recognition theories attempt to explain the process of perception, which includes visually observing an object, creating a mental image of the object, and comparing this image to other stored images. Categorization theories address how humans use categories to classify objects (Markman and Ross 2003; Tarr and Bulthoff 1998).

Modern object recognition theory, known as objectcentered theory, was popularized by Marr's Vision (1982). Marr theorized that human perception happens in a series of steps, which allows a three-dimensional object and the area around it to be reconstructed in the memory (Tarr and Bulthoff 1998). This object-centered theory (also known as structural description theory) explains that human recognition begins with a series of primitives (mental representations of the basic visual properties of an object). Collectively, these primitives form a $2^{1 / 2} \mathrm{D}$ mental sketch called a primal, which includes information about the object and the surrounding space. Once a representation of a specific object was formed, any further observations of the object would be recognizable, independent of the direction from which the object is viewed (Marr 1982).

Marr's work led to modern object-centered theories of human recognition such as Biederman's (1987) rec- ognition by components (RBC) theory. The RBC theory proposes that humans recognize and perceive three-dimensional geons (cylinders) from objects and store these shapes in memory for recognition. This storing of shapes eases the recognition of objects and allows people to recognize a three-dimensional object even though it may be rotated or occluded in some way (Biederman 1987).

A second category of object recognition theories is known as view-based theories. View-based theories propose that three-dimensional objects are represented in the brain in several two-dimensional views. Thus, contrary to object-centered theory, multiple views from varying angles are thought to be essential for the proper formation of mental representations of threedimensional objects (Tarr 2003; Ullman 1998).

Perception is only one component of the identification process. The second component of object recognition is categorization. Categorization is the process of determining whether an object is a member of a category by comparing it to a conceptual representation (Lin and Murphy 1997). The ability to categorize is an integral part of cognitive ability as it allows for classification, inferences, reasoning, visual perception, and object identification (Sakamoto and Love 2003; Yamauchi and Markman1998). Categorization is relative to all cognitive processes. These categories are formed through prior experience and are stored in the memory (Peters et al. 2003).

Generally, there are two theories addressing how various concepts (categories) are represented in memory. Exemplar theories propose that visual stimuli (in this study, insect specimens) are perceived and compared to an exemplar (a single instance of stored features that represent a category) (Markman and Genter 2001; Medin and Schaffer 1978; Nosofsky 1986). Classification is based on the similarity of the visual stimuli to exemplars (Nosofsky 1987; Nosofsky et al. 1989). The representation of an exemplar is refined as more instances of an object category are seen and through the process of classification itself (Markman and Ross 2003).

In contrast, prototype theories propose that visual stimuli are compared to a stored central tendency of features that represent a summary of the most typical features that compose a category. Stimuli are classified based on their similarity to the summarized prototypical category (Markman and Genter 2001; Nosofsky and Zaki 2002). Like exemplars, prototypical categories change as new instances of the category are encountered and through the process of classification.

Theories relating to human object recognition and categorization are important in understanding the possible cognitive processes that occur as humans perform an identification task, like insect identification. However, they do little to explain the specifics involved in transitioning from a novice learner to an expert in 
identifying particular objects (i.e., insects). As the goal of this study was to examine different instructional approaches and their impact on student insect identification performance, an examination of expertise in object recognition is important.

Risenhuber and Poggio (2000) note that humans can learn to recognize an object even after a brief exposure. However, learning to identify a specific object and becoming an expert in identifying that type of object are very different tasks. Defining the specific qualities of an expert identifier is difficult. Expertise is often quantified by the measurements of identification accuracy and the speed at which objects are identified (Biederman 1987; Biederman and Shiffrar 1987; Draper et al. 2004; Yamauchi and Markman 1998). Both the accuracy and speed at which objects are identified are dependent upon the number of times (frequency) a category of objects has been previously seen (Rosch 1978).

Experts typically identify and categorize objects faster than novices (Draper et al. 2004). What causes the higher speed and accuracy of identification in experts? Pylyshyn (2003) states that expert perceivers do not have a better method of observing objects than novices. Experts simply know where to look for patterns and are more aware of which characters are important in achieving correct identification. Pylyshyn points to expert birders and plane spotters who are able to recognize patterns and shapes that novices cannot easily see. Experts are able to identify objects more quickly and accurately as a result of selectively attending to certain perceptual cues (Pylyshyn 2003). Goldstone (1998) refers to this as attentional weighting (selective attention), as experts can learn to direct their attention to the features that are important to identification while decreasing attention to unimportant perceptual features.

While knowledge of diagnostic cues is necessary for identification, Blair (2004) found that learners (novices) tended to use only one cue when categorizing fictionalized objects. Participants in Blair's study tended to rely on one diagnostic cue even following prior training on a number of relevant cues. Therefore, Blair concluded that novices tended to limit the number of cues they use to identify objects, even though they were trained to recognize more characters and were aware that using these characters would increase their accuracy.

Performance measurements, such as speed and accuracy of identification, are helpful in evaluating expertise in identification. However, these measurements explain little about what qualities expert perceivers posses in identifying biological organisms. Fortunately, a few studies have examined the concept of expertise in the context of biological identification. These studies highlight several additional qualities of expert biological identifiers, which are most relevant to the task of insect identification.
Several authors suggest that in object categorization tasks, novices rely predominantly upon visual similarity when recognizing objects, while experts use both similarity and experiential knowledge about the objects (Proffitt et al. 2000; Shafto and Coley 2003). Shafto and Coley (2003) tested novices' (undergraduate students) and experts' (commercial fishermen) abilities and methods of classifying fish. On an open-ended sorting task, they found that novices tended to classify the fish on the basis of their appearance, while experts tended to sort the fish based on ecological, biological, and behavioral relationships, in addition to similarity of appearance. The authors' conclusion was that what defines the transition from novice to expert is not the abandonment of relying upon visual similarity when making categorization decisions, but the augmentation of this method with other knowledge related to the object category (Shafto and Coley 2003).

Horsey (2002) examined professional chicken sexers' ability to discriminate between male and female day-old chicks. When experts were asked how they discriminate male from female chicks, they were unable to explain the process. Experts were simply able to look at the chick and somehow discriminate gender. Chicken experts spend up to 2 years in training to become proficient (near $100 \%$ correct identification) discriminating gender at the rate of $800-1,200$ chicks per hour. Horsey's conclusion was that in the case of diagnostic cue acquisition for this particular task, a great deal of time, training, and observation is required to identify diagnostic cues.

To develop methods of improving student performance in insect identification tasks, the causes of student misidentification is also necessary. Borror and White (1970) state that identification of insects is similar to other forms of life, in that "it simply is a manner of knowing what to look for and being able to see it (p. 1)." While this statement seems to simplify the task of insect identification, there are several factors which complicate their identification.

One factor which often leads to insect misidentification is failure to fully examine the morphological characters of the specimen. In their experience, many instructors feel that students simply look at the shape and general appearance of an insect, instead of examining all the key characters of a specimen during identification. While the general appearance (shape, color, size) is an important character in the identification of insects, these characteristics do not provide all the information necessary for correct taxonomic identifications. Often use of a diagnostic key is necessary to positively identify an insect. Subsequently, sight identification using key characters and general appearance can be used to identify individual taxa (Johnson and Triplehorn 2005; Turpin 1997). 
Blair (2004) found that in example stimuli (fictional created objects), participants often relied on only one character to classify the stimuli, even at the expense of accuracy. However, knowing all the morphological characters is not necessary for the identification of some insect taxa, as one characteristic, such as the snout in Curculionidae (weevils), is often sufficient to identify this family of beetles (Dunn 1994). Dunn (1994) also states that, "the trick to insect identification is to learn the conspicuous and reliable features that are associated with each particular order and/or family (p. 20)."

Another factor that may cause students to misidentify insects is a lack of studying or preparation. The general perception of many instructors is that when students fail in insect identification tasks, they have not spent enough time studying. The underlying belief of instructors is that much of the knowledge needed for correct identification (key character, general appearance, scientific names, group categorization knowledge, and structure knowledge) is learned and retained through memorization. In support of this, many of the teaching tasks in insect identification focus on memorization activities, such as learning through flash cards and memory games (Dunn 1994).

A final reason why many students fail to correctly identify insects is that they have never seen a particular form of an insect before. Much emphasis in introductory insect identification courses is placed on providing students with many examples of insects that belong to each taxonomic group (Dunn 1994). In this manner, is assumed that the more examples of diversity of forms in each insect taxa to which students are exposed, the better they are able to classify an insect.

The main purpose of this study was to determine whether undergraduate students that received webbased instruction on either traditional, key character, or classification instruction differed in their ability to identify insects.

The traditional instruction group was presented with line drawings, a widely used instructional material offered in insect identification courses. Line drawings contained two-dimensional black and white depictions of insects, with characteristics labeled. Line drawings were taken from open-source publications.

The key character instructional exercises used in this study trained students to look for morphological characters on pictorial specimens (specimens presented through pictures). Knowledge of key morphological characters is important for the identification and categorization of insects (Dunn 1994). The purpose of these exercises was to give students practice in looking for morphological characters and to teach them which characters were necessary for positive identification at the arthropod class, insect order, and insect family levels. It was hoped that practice of the task of looking for these characters transfers to students' ability to look for characters on prepared specimens, thereby improving identification performance.

Knowledge of key morphological characters is important for the identification and categorization of insects (Dunn 1994). The key character instructional exercises used in this study trained students to look for morphological characters on pictorial specimens (specimens presented through pictures). The purpose of these exercises was to give students practice in looking for morphological characters and to teach them which characters were necessary for positive identification at the arthropod class, insect order, and insect family levels. It was hoped that the practice of the task of looking for these characters would transfer to students' ability to look for characters on prepared specimens, thereby improving identification performance.

Schyns (1998) states the importance of diagnostic cues in object recognition as they are the first input to object categorization. Knowing which diagnostic cues to attend to, and when, is a characteristic of expert identifiers (Goldstone 1998; Pylyshyn 2003). The instruction presented in the key character exercises was designed to provide knowledge of the diagnostic cues and help learners selectively attend to those features necessary for identifying insects, thus improving insect identification performance.

Categories are formed by a person's interactions with objects from various categories and with objects from the same category (Markman and Ross 2003). Classification is the ability to determine that a new instance is a member of a known category. Practice in classifying objects has been shown to impact category formation and category predictions (Markman and Ross 2003; Yamauchi and Markman 1998). The classification learning instruction presented in this study was similar to that presented in Yamauchi and Markman's (1998) study. In our example, students were presented with an exemplary pictorial specimen of the insect or arthropod taxa and then were asked to classify a set of target pictorial specimens.

The second purpose of this study was to determine whether student performance varied based on the level of taxonomic classification (class, order, and family) in which they are asked to identify insects to. The assumption is that as the taxonomic level approaches family, the task of identification would be more difficult because the visual similarity of insects is greater.

The third and final purpose of this study was to determine whether misspelling or misidentification errors accounted for a greater percentage of incorrect responses on prepared specimen quizzes. Correctly identifying specimens by writing the scientific names of specimens is the performance measure of in-class specimen identification quizzes. Thus, it was important to determine 
whether missed specimens were a result of students not knowing the identification of the specimen or not knowing how to spell the specimen name.

Web pages were used for the delivery of the instruction in this study because of their unique capabilities. An assumption of this study regarding why students might be performing below expectations was because they did not have access to prepared specimens outside of class. Limited exposure to specimens outside of the traditional classroom is viewed as an obstacle in students learning insect identification. The instruction presented in this study took advantage of the World Wide Web's capabilities and presented pictorial specimens (pictures of insects at dorsal, ventral, lateral, anterior, and posterior views) as a part of this instruction. Web pages were also used as they can be accessed outside of class time and are available anytime of the day (Brooks et al. 2001). There are also many examples of Web sites created to teach insect identification (Hai-Jew 2011; Insects ID, insectidentification.org 2012; Stanley et al. 1996). In this study, we used a custom Web site for exercise delivery.

\section{Methodology}

Participants were undergraduate students enrolled in four sections of an introductory entomology identification course at a large Midwestern university. Participants were enrolled in a wide range of science and nonscience majors and represented a variety of academic class standings. The total number of participants was 49. Although participation in the study was voluntary, completion of the web-based instruction was assigned as a part of the course curriculum to encourage students to complete the exercises outside of class.

Once informed consent was received, participants were randomly assigned, within each course section, to one of three different types of web-based instructional exercises: traditional (control), key character, or classification instruction for the duration of the study. These exercises were presented in addition to the instruction students received as a part of the traditional insect identification course. Exercises were delivered through a Web site driven by Lasso Professional 6 software (LassoSoft Inc.) with activity data stored in MYSQL databases.

During each week in which web-based additional instruction was provided, students were first presented with in-class identification instruction covering arthropod or insect groups. Following the in-class instruction, students were required to complete web-based exercises at any time during a one-week period. The web-based insect identification instruction covered taxa presented during the previous week's class. Dur- ing class, the following week, students completed an in-class-prepared specimen quiz over the taxa presented in the previous week's class session, those covered in the web-based exercises.

Arthropod and insect groups used in this study were chosen as they represented different levels of taxonomic classification, with each level of classification including more characters necessary to describe and identify a specimen. These groups were already a part of the course instruction and their use and order of presentation did not greatly interfere with how the course was traditionally taught. Two class sessions of insect orders were included in this experiment because they represented very different insects. One session included insect groups, insect orders (1) were presumably less familiar to students: Ephemeroptera (mayflies) and Plecoptera (stoneflies). The other session, insect orders group (2), covered commonly occurring insects likely familiar to students: Hemiptera (true bugs) and Homoptera (aphids, leafhoppers, and scales) and Isoptera (termites).

At the beginning of each week, students completed a web-based multiple choice pre-quiz in which they identified a series of pictorial specimens. Pictorial specimens were represented in a series of still photographs with magnified views of prepared specimens (Figure 1). Each pictorial specimen was first presented with a picture of the dorsal (top) view, with hyperlinks to pop-up windows containing pictures of the ventral, lateral, posterior, and anterior views.

Students were asked to answer which class, order, or family the pictorial specimen belonged to by selecting one of four answers. Quizzes could only be taken once and were composed of 10 questions. Students were not provided feedback on responses to questions. Backtracking of questions was not allowed. After completing the pre-quiz, students were given access to the instructional exercises.

Treatment assignment was constant for participants throughout the duration of the study. The total number of exercises in the web-based exercises varied each week and was dependent upon the number of taxonomic groups covered in a particular week's class session. The number of exercises presented in the key character and classification treatment groups matched the number of different pictorial specimens presented (two) for each of the taxonomic groups. Pictorial specimens presented in the key character and classification instruction were identical, and the traditional instruction had no pictorial specimens.

Traditional Instruction

Participants assigned to the traditional treatment viewed and studied a series of line drawings. These 
Figure 1 Pre-quiz

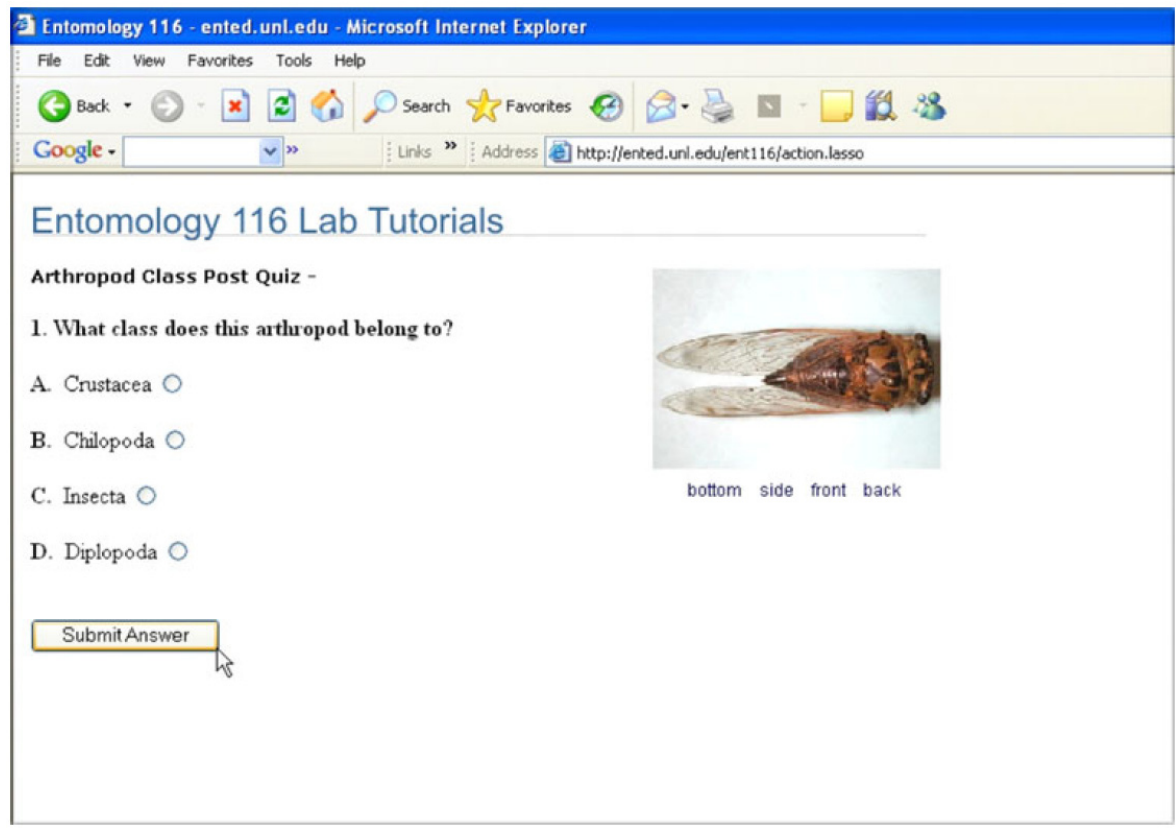

Figure 2 Key character exercise with pictorial specimen

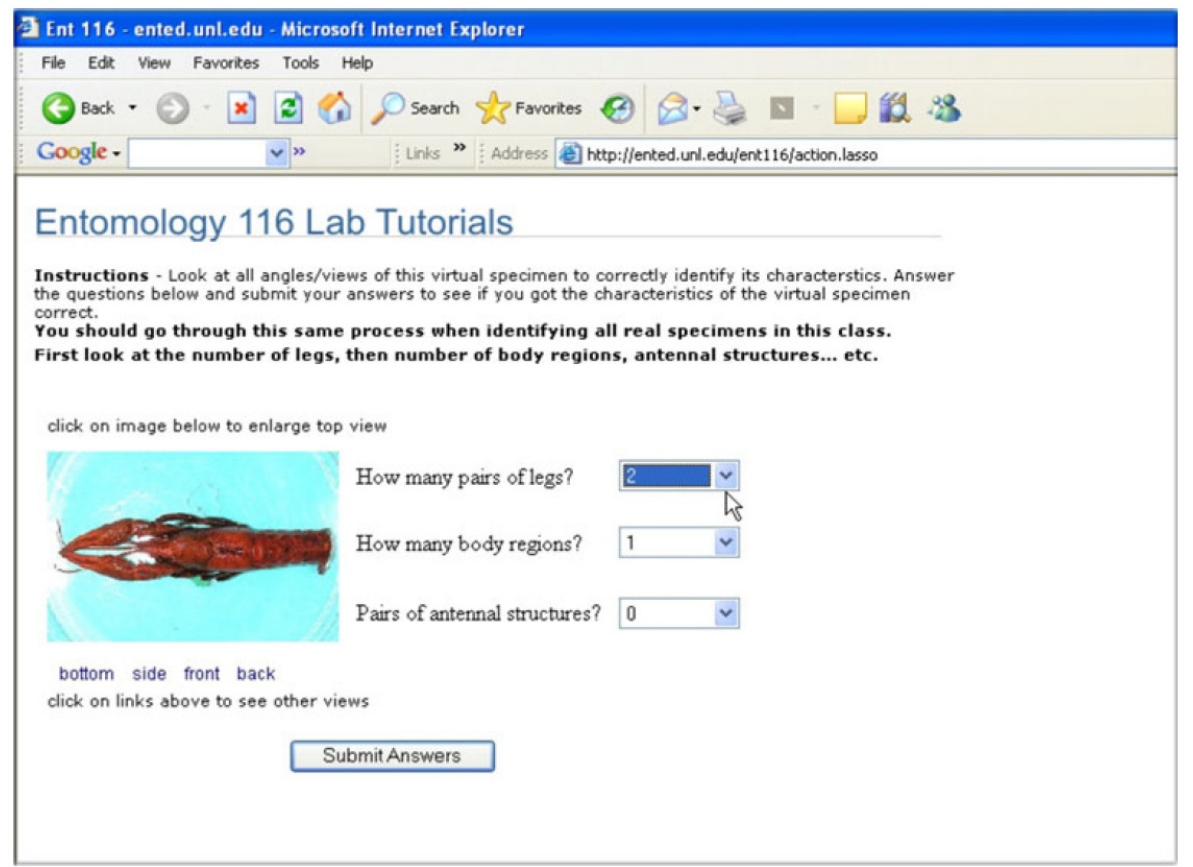

line drawings were scanned images presented through the web page in jpeg format and were static (no interactivity). The line drawings were identical to those given to all students in their course packets. Line drawings contained text information on key characters useful in identifying specimens belonging to an arthropod group. Text instructions at the top of the web page directed students to study and review the line drawings for 2 min each. However, students could review materials for any duration of time. A button at the bottom of the web page screen allowed students to finish examining the line drawing, taking them back to the list of exercises in the student account home page. Students were then instructed to complete all exercises in any order. Since the line drawings utilized in the webbased instruction were identical to those presented in class, no new information was presented to students in traditional instruction group. The traditional instruction group served as the control for this study.

\section{Key Character Instruction}

Participants assigned to the Key Character Identification instruction group completed exercises requiring 
them to choose key morphological characters belonging to pictorial specimens. The characteristics they were instructed to identify were those characteristic of all arthropods or insects belonging to the target taxonomic group. At the beginning of the exercise, students were not provided the name of the target taxonomic group to which the pictorial specimen belonged.

Therefore, students were required to examine the specimen's key morphological characters in order to determine its proper classification. The purpose of the key character exercises was to ask students to look for, and identify, the key morphological characteristics belonging to the pictorial specimen (Figure 2).

After visually examining the pictorial specimen, students were instructed to choose the appropriate identification characters of the specimen. Students selected characters for pictorial specimens by picking responses in a scrollable input field. Students were required to identify three characters of pictorial specimens in the arthropod class week, six for insect order weeks, and 10 for insect family level. When students finished selecting characters for the pictorial specimen, they submitted their results by pushing a button at the bottom of the web page. They were then taken to a page that gave them feedback on their character selections.

If participants incorrectly chose a character, a red " $x$ " was placed next to the input field, indicating that the chosen character was wrong. If students incorrectly selected any one character of the pictorial specimen, they were prompted with a text message to repeat the exercise until they correctly selected all characters.

If students correctly entered all the characters belonging to the pictorial specimen, they were informed of their success, and taken to a web page of line drawings, identical to those presented to the traditional instruction group, for the pictorial specimen's taxonomic group. Students were asked to review the line drawing for $1 \mathrm{~min}$ and were allowed to continue at anytime onto the next exercise by clicking a button at the bottom of the web page.

\section{Classification Instruction}

Participants assigned to the classification instruction completed exercises requiring them to identify which of six pictorial specimens belonged to a target taxonomic group. The goal of this instruction was for students to practice making determinations about which specimens belonged to the target taxonomic group and which did not. This task is similar to the determinations that students made when taking the in-class specimen identification quizzes.

At the beginning of the exercise, students were presented with line drawings and character information about the target group. These line drawings were identical to those presented in the control and key character group exercises. Students were asked to review the line drawings for $1 \mathrm{~min}$ and could continue at any time by
Figure 3 Specimens in classification instruction exercise

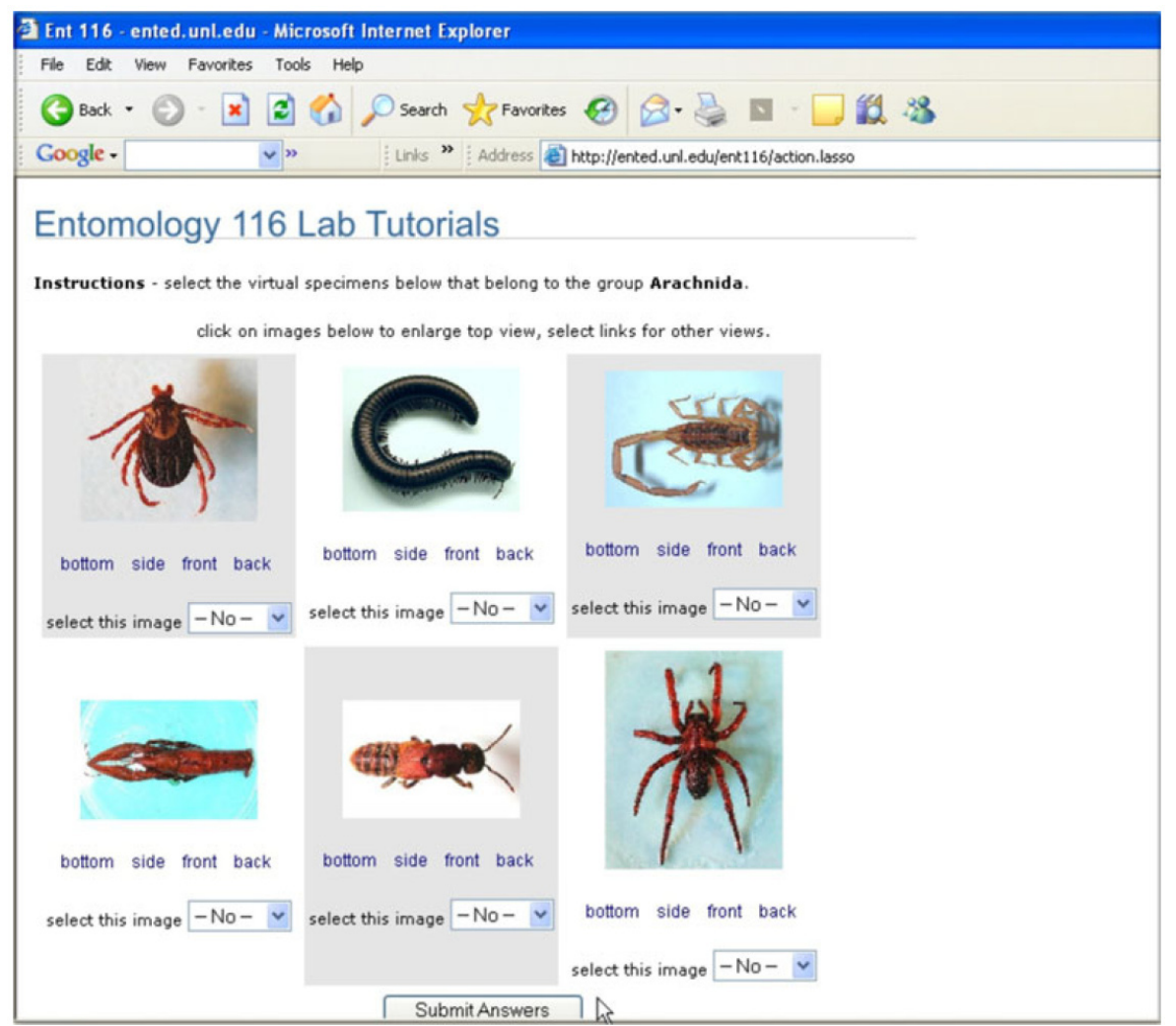


clicking on a button at the bottom of the web page. After clicking the button, participants were taken to another web page where they were shown six pictorial specimens. Students were then asked to identify those specimens that did, and those that did not, belong to the target group shown in the line drawings on the previous web page (Figure 3). Students then selected membership to the target group by selecting either "yes" or "no" in scrolling input fields. After students assigned target group membership to all six pictorial specimens, they submitted their results. They were then taken to a web page where they received feedback on their choices. If any of the pictorial specimens were not placed in the correct target group, students were informed with a text message that at least one specimen was incorrectly placed. Students were required to repeat the exercise until they had correctly placed all specimens in their proper groups.

When participants in the control and treatment groups completed all of the exercises, they were prompted to finish the exercises by completing the web-based insect identification post-quiz. The post-quiz was identical to the pre-quiz students took when they first entered the student account manager home page. Upon completion of the post-quiz, students completed the requirements of the week's exercises.

During laboratory sessions following the introduction of new taxonomic groups and after the web-based instruction was completed, participants took the inclass prepared specimen identification quizzes. These quizzes covered the taxonomic orders presented in the previous week's in-class and web-based instruction. In-class prepared specimen identification quizzes were in the traditional format assigned as a part of the course curriculum. Students were given a set of prepared specimens identified by a single letter. Students identified specimens by writing the scientific name of the specimen in the blank corresponding to specimen's letter label, on the quiz sheet. All quizzes were identical for each course section and for all students regardless of treatment group. All specimens presented in laboratory quizzes were unique to those presented to in-class and presented in the web-based instruction. The purpose of unique specimens was to help ensure that the quizzes were testing the identification of the novel specimen and not memorization of some feature of a prepared specimen students had seen previously in class such as unique mounting or pinning, crack in a slide, color of a stopper in a specimen vial, or positioning of a particular specimen's appendages.

\section{Data Collection}

Students' identification performance was assessed based on their ability to identify and correctly spell the taxonomic name of prepared specimens in corresponding blanks provided on the quiz sheet. Identifications were considered correct if the specimen was correctly identified with correct spelling. Identifications were considered incorrect if the specimen was correctly identified, but the name was misspelled ( $\leq 3$ incorrect or misplaced letters in the taxonomic name) or if the specimen was misidentified ( $\geq 4$ incorrect or misplaced letters in the taxonomic name, had incorrect scientific name, or was left blank). The total number of correctly identified, misspelled, and incorrect specimens was recorded for each student, each week of the study.

In addition to performance on in-class prepared specimen quizzes, measurements of identification performance were also gathered immediately before and after the web-based instruction. While the web-based quiz did not use live specimens or require students to write the scientific name like the in-class prepared specimen quizzes, it provided a measure of students' immediate learning as a result of the web-based instruction. Data on the number of correct responses were collected for the web-based pre-and post-quizzes.

Results

Web-Based Quizzes

A mixed randomized repeated analysis of variance was conducted utilizing classification level (arthropod classes, insect orders (1), insect orders (2), and insect families) as the within factor and web-based insect identification instruction (Treatment) as the between factor. The dependent variable was the change in the number of correctly identified pictorial specimens from pre-quiz to post-quiz. Mauchly's test of sphericity was significant $p=0.003$, indicating a violation of homogeneity. Therefore, a Huynh-Feldt (H-F) correction for adjusted probability of $\mathrm{F}$ was used in accordance with recommendations made by Tabachnick and Fidell (2001). The Classification Level main effect and Classification Level $\mathrm{x}$ Treatment interaction was tested using the multivariate criterion of Huynh-Feldt $(\mathrm{H}-\mathrm{F})$. The Classification Level main effect was nonsignificant, $\mathrm{H}-\mathrm{F}$ adjusted $F(2.581,141)=0.641, p=0.567$. The Classification Level $\times$ Treatment interaction was nonsignificant, $\mathrm{H}-\mathrm{F}$ adjusted $F(5.162,141)=1.214, p$ $=0.306$. The univariate test associated with the Treatment main effect was also nonsignificant, $F(2,47)=$ $1.260, p=0.293$.

Although there was no significant interaction between Classification Level and Treatment, the assumption that students' ability to correctly identify insects improved from pre-quiz to post-quiz regardless of the web-based instruction was also analyzed. A paired samples $\mathrm{t}$ test was conducted for each classification 

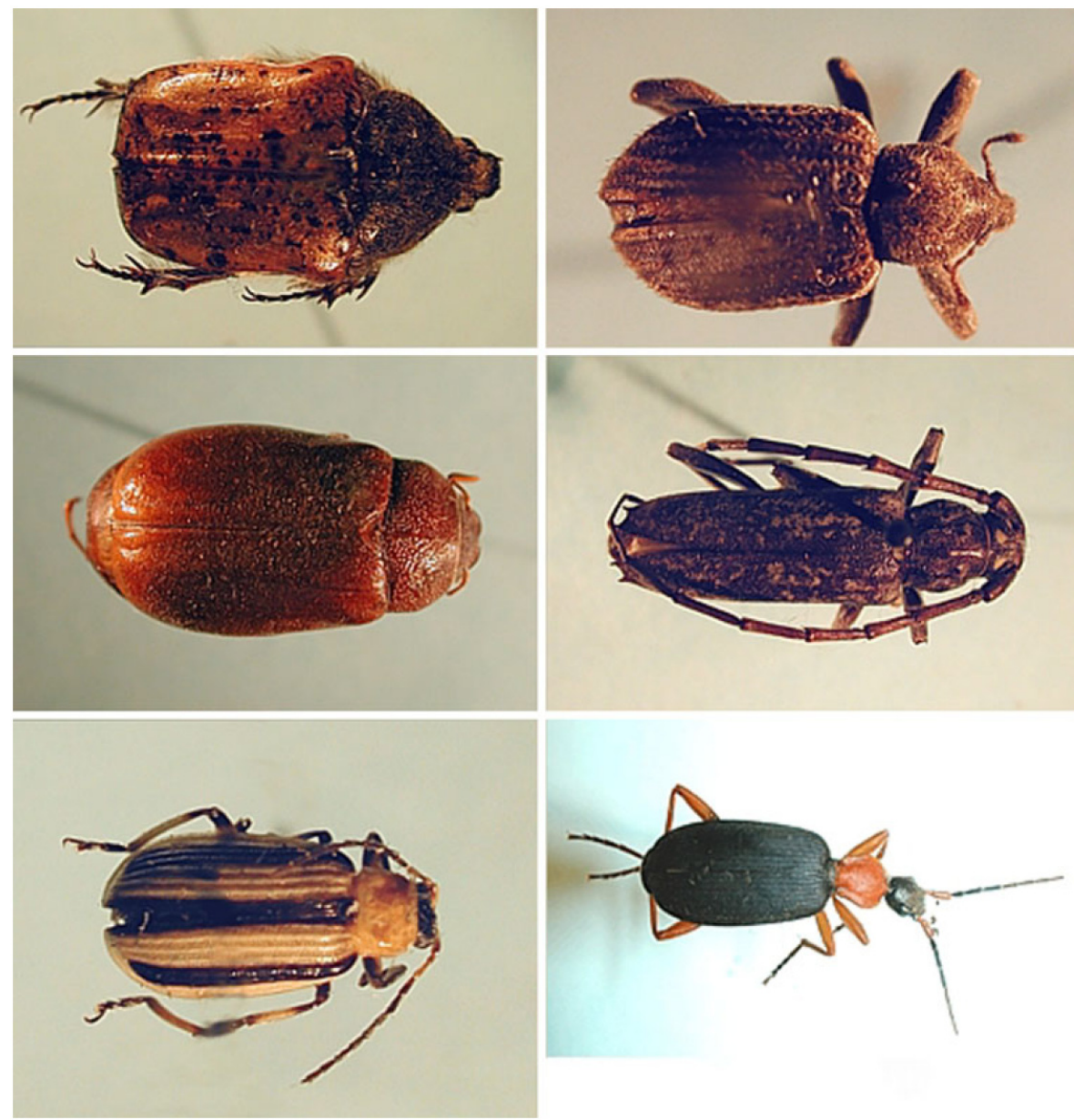

Figure 4 Insect families (dorsal view)e

level (arthropod classes, insect orders (1), insect orders (2), and insect families) to determine whether there was an increase in the number of correctly identified pictorial specimens from pre-quiz to post-quiz. The results indicated that for the arthropod classes, the mean number of correctly identified specimens on the post-quiz $(\mathrm{M}=9.72, \mathrm{SD}=0.607)$ was significantly greater than the mean number of correctly identified specimens on the pre-quiz $(\mathrm{M}=8.92, \mathrm{SD}=1.259), t(49)$ $=4.484, p=0.000$. Cohen's d standardized effect size was 0.691 , with considerable overlap in the distribution from pre-quiz to post-quiz. The $95 \%$ confidence interval for the mean difference between the pre-quiz and post-quiz was -1.16 to -0.44 .

For the insect orders (1), results indicated that the mean number of correctly identified specimens on the post-quiz $(\mathrm{M}=6.10, \mathrm{SD}=1.418)$ was significantly greater than the mean number of correctly identified specimens on the pre-quiz $(\mathrm{M}=5.28, \mathrm{SD}=1.874), t(49)$ $=3.846, p=0.000$. The standardized effect size, $d$, was 0.549 , with considerable overlap in the distribution of correctly identified pictorial specimens from prequiz to post-quiz. The $95 \%$ confidence interval for the difference between the two groups was -1.25 to -0.39 .

For the insect orders (2), results indicated that the mean number of correctly identified specimens on the post-quiz $(\mathrm{M}=5.88, \mathrm{SD}=1.335)$ was significantly greater than the mean number of correctly identified specimens on the pre-quiz $(\mathrm{M}=4.58, \mathrm{SD}=$ $2.081), t(49)=5.111, p=0.000$. The standardized effect size, $d$, was 0.730 with considerable overlap in the distribution of correctly identified pictorial specimens from pre-quiz to post-quiz, as shown in Figure 4 . The $95 \%$ confidence interval for the mean difference between the two groups was -1.81 to -0.79 .

Results regarding the insect families indicated that the mean number of correctly identified specimens on the post-quiz $(\mathrm{M}=7.16, \mathrm{SD}=2.351)$ was significantly greater than the mean number of correctly identified pictorial specimens on the pre-quiz $(\mathrm{M}=6.08, \mathrm{SD}=$ $2.372), t(49)=3.267, p=0.000$. The standardized effect size, $d$, was 0.467 with considerable overlap in the distribution of correctly identified pictorial specimens from pre-quiz to post-quiz, as shown in Figure 4. The $95 \%$ confidence interval for the mean difference between the pre-quiz and post-quiz was -1.74 to -0.42 . 


\section{In-Class Quizzes}

A mixed randomized repeated analysis of variance was conducted utilizing levels of classification as the within factor and web-based insect identification instruction as the between factor. The dependent variable was the percent of prepared specimens correctly identified. The dependent variable was negatively skewed; therefore, an arcsin transformation was conducted to normalize the distribution of the scores. This transformation was consistent with recommendations made by Little and Hills (1978). Mauchly's test of sphericity was not significant $p=0.116$, indicating no violation of homogeneity. The Classification Level main effect and Classification Level 9 Treatment interaction were tested using the multivariate criterion of Wilk's lambda. The Classification Level main effect was significant, $\Lambda=0.480, F(3,141)=16.258, p=0.000$, multivariate $\eta^{2}=0.52$. The Classification Level $\times$ Treatment interaction was nonsignificant, $\Lambda=0.837, F(6,141)=$ $1.396, p=0.225$. The univariate test associated with the Treatment main effect was nonsignificant, $F(2,47)=$ 2.252, $p=0.116$.

Pairwise comparisons (paired $t$ tests) were conducted to follow up the significant main effect for Classification Level. To control for Type 1 (family wise) error as a result of multiple comparisons, the Holm's sequential Bonferroni procedure was used according to recommendations made by Green and Salkind (2010). The results of the analysis are shown in Table 1.

Comparison of Misspelled Versus Misidentified Specimens

Raw percentages were calculated for both misspelled and misidentified specimens from the total number of incorrect responses on the arthropod classes, insect orders (1), insect orders (2), and insect families. Separate paired $t$ test analyses were conducted for the comparison of misspelled and misidentified specimens for arthropod classes, insect orders (1), insect orders (2), and insect families. There was a significantly greater percentage of misidentified specimens $(\mathrm{M}=87.8 \%$, SD $=21.2 \%)$ than misspelled specimens $(\mathrm{M}=12.2 \%, \mathrm{SD}=$

Table 1 Experiment 1 in-class prepared specimens

$\begin{array}{lr} & \mathrm{M} \\ \text { Post hoc analysis classification level main } & \text { effect } \\ \text { Arth. classes-orders 1 } & 0.044 \\ \text { Arth. classes-orders 2 } & 0.089 \\ \text { Arth. classes-I. Families } & 0.297 \\ \text { Orders 1-orders 2 } & 0.045 \\ \text { Orders 1-I. Families } & 0.253 \\ \text { Orders 2-I. Families } & 0.208\end{array}$

SD

0.330

0.286

0.307

0.398

0.358

0.365
$21.2 \%), t(29)=2.73, p=0.000$, on the arthropod class quiz. The $95 \%$ confidence interval for the mean difference between misspelled and misidentified was -92.8 to $-52.6 \%$. There were no significant differences in the percentage of misidentified specimens ( $\mathrm{M}=63.5 \%$, SD $=45.9 \%$ ) and the percentage of misspelled specimens $(\mathrm{M}=36.5 \%, \mathrm{SD}=45.9 \%), t(31)=1.662, p=0.107$, for the insect orders (1) quiz. The $95 \%$ confidence interval for the mean difference between misspelled and misidentified was -60.1 to $6.1 \%$. In the insect orders (2) quiz, there was a significantly greater percentage of misidentified specimens $(\mathrm{M}=84.7 \%, \mathrm{SD}=26.0 \%)$ than misspelled specimens ( $M=15.3 \%, \mathrm{SD}=26.0 \%), t$ $(40)=8.361, p=0.000$, on the arthropod class quiz. The $95 \%$ confidence interval for the mean differences between misspelled and misidentified was -84.6 to -51.7 $\%$. Finally, there was a significantly greater percentage of misidentified specimens ( $\mathrm{M}=80.7 \%, \mathrm{SD}=28.6 \%)$ than misspelled specimens $(\mathrm{M}=19.3 \%, \mathrm{SD}=28.6 \%), t$ (42) $=7.042, p=0.000$, on the insect family quiz. The 95 $\%$ confidence interval for the mean differences between misspelled and misidentified was -79.0 to $-43.8 \%$.

\section{Discussion}

There were no significant differences in students' insect identification performance on either the webbased pictorial specimen quizzes or the in-class prepared specimen quizzes as result of the type of webbased instruction they received. There are several possible explanations for this result. First, it is possible that each of the various treatment groups (traditional, key character, and classification instruction) had either no impact, or a similar impact, on student performance. It is possible that the traditional (control group) instruction did, in fact, impact student learning, and that this impact was similar to that of the key character and classification instruction groups.

Secondly, web-based instruction was presented in addition to more extensive instruction received by students in class. It is possible that students not only received, but retained, much of this initial learning gained in-class instruction. This would leave little room for additional learning to occur as a result of the

a Sig. Holm's sequential Bonferroni procedure 
web-based instruction. The additional instruction was also very short in duration, requiring $10 \mathrm{~min}$ or less to complete, and had a limited number of exercises (no more than 10 in any 1 week). The obvious argument is that this amount of instruction is simply not enough to impact performance in the face of other, more extensive instruction, such as that presented in class.

Although key characters have traditionally been assumed to be important for insect identification (Dunn 1994), a third possibility is that the key character and classification instruction are not that important for novice insect identifiers. Schyns (1998) states diagnostic cues, similar to insect key characters, are an important component to diagnostic classification. Furthermore, expert identifiers know which diagnostic cues to attend to and when (Goldstone 1998; Pylyshyn 2003). Based upon the results from this study, key character instruction may not be the best instructional approach for students new to insect identification. Those new to the task of insect identification do not consistently know which diagnostic characters are associated with each taxonomic group and lack an understanding of insect morphology, whereas taxonomists and experienced insect identification students do. The other possibility is that contrary to popular belief, key characters instruction alone is not enough to significantly impact learning associated with identification for novice insect identifiers.

The main effect of classification instruction was also not significantly different from the other instruction methods. Like key character instruction, it is possible students have to attain a level of expertise not achieved in this study to utilize the classification instruction. The other possibility is that classification instruction alone is not enough to impact learning. In Yamauchi and Markman's (1998) study, Classification Learning, Inference Learning, and a combination of the two learning techniques were studied. While not tested in our study, it is possible that students would learn the most from a combination of both key character and classification instruction. Future studies should weigh the expertise level of students and the learning techniques used. Further, this research suggests a combination of interventions should be investigated.

Although overall no significant differences in student performance on insect identification existed between web-based instruction groups, examination of webbased pre-and post-quiz scores regardless of treatment group indicates that learning occurred. Separate analysis of web-based quiz scores by classification level revealed a significant increase in the number of correctly identified pictorial specimens from pre-quiz to postquiz. This suggests that the web-based instruction did improve student performance on pictorial specimen identification. Performance of in-class pre-quizzes may have revealed lower overall scores than post-quizzes (as observed in the web-based quizzes) indicating that learning did occur.

There was a significant main effect in student performance on in-class prepared specimens among the different classification level tasks, $\Lambda=0.480, F(3,141)$ $=16.258, p=0.000$. Students in all treatment groups demonstrated a significantly higher percentage of correctly identified specimens in the arthropod classes, insect orders (1), and insect orders (2), than compared to the insect families. Students' performed significantly worse on identification of insect families than any of the other classification groups. Several factors regarding insect family recognition may explain why this task was more difficult. First, four out of the five family names started with the letter c. To a novice, Carabidae, Cerambycidae, Chrysomelidae, and Curculionidae are all very similar in pronunciation and spelling, perhaps making them more difficult to learn. In addition to the difficulty of spelling, the insect families are also the most similar in appearance to one another, in comparison with the other classification groups. This adds to the difficulty of distinguishing each family from one another. While it is hard to quantify the visual similarity of the insect families as compared to the other groups presented in this study, a glance at these specimens in Figure 4 provides a subjective comparison of these similarities.

Due to the confines of the course used in this study, we did not assign the order in which the arthropod classes, insect orders (1), insect orders (2), and insect families were presented. There may be some relation among the order in which these groups were presented in this study and student identification performance. Tabachnick and Fidell (2001) refer to this as a position effect. Perhaps, students became complacent as the semester wore on, thus affecting the performance on insect family identification, as this group was presented last.

Even though the order in which the classification groups were presented and when in the course of the semester they were presented likely had some impact on student performance, we argue that students' increased expertise gained over the course of the semester in identifying insects and observing key characters, likely had a much larger impact on student performance. The fact that students correctly identify fewer specimens on the insect family quiz suggests that even in the face of an assumed increase in expertise, student performance in correct identifications declined. This supports the position that insect families were more difficult for students to identify, explaining the poorer performance as compared to the arthropod classes, insect orders (1), and insect orders (2).

A significantly greater percent of identification errors were due to misidentification, as opposed to mis- 
spelling, for class orders, insect orders (2), and insect families. Overwhelmingly, there was a significantly greater percentage of misidentified as opposed to misspelled specimens. For insect orders group (1), no statistically significant differences were found in the percentage of misidentified compared to the percentage of misspelled specimens. This may be a result of this group having four insect orders, lessening the chance for variance. The other weeks had five or more orders for students to learn. Also, in insect orders (1), two of the orders had similar scientific names-suborders Anisoptera and Zygoptera - with a higher percentage misspellings of scientific names.

The web-based instruction presented in this study was not designed to reinforce proper spelling, as students were not required to correctly spell insect names to complete the exercises, but were only required to select an insect name from a list of choices. However, it is possible that simply having the increased opportunity to repeatedly view the correct spellings while completing the web-based exercises may actually have resulted in fewer spelling errors on the in-class quizzes. Spelling of the scientific name is an important part of the inclass identification task. As the interventions did not focus on reinforcement of spelling the fact that more errors are a result of misidentification are surprising. It may be that the scientific names are so difficult for some that students "draw a blank" and do not provide an answer. For others, they do not know what it the insect is. Examining the responses of students shows that there is a clear delineation in how students err. Students leave the answer blank, misspell the name, or put the wrong scientific name for the examples. In support of these distinctions, examples of recorded misspelled names for some of the insect groups are found hereathttp://scitechteach.org/insectid/spellings.pdf.

A second explanation for these results is simply that the main reason for students incorrectly identifying insects is because misidentifications (not spelling errors) are the most common errors that students make on prepared specimen quizzes. An argument as to why a significantly smaller percentage of misspelled specimens occurred may be that the specifications used to define misspellings versus identification errors are not representative of students' incorrect responses. Spelling errors were defined as those specimens that were incorrect with three or less misplaced or misspelled letters in the taxonomic name. It is possible that four or less misplaced or misspelled letters in the scientific name is more representative of misspelled specimens versus misidentified specimens. However, based on a pilot study, the criteria established for misspelling and misidentification errors appeared to be the representative of what was truly occurring when students gave incorrect responses. Nonetheless, creating a workable delineation between mis- spelled taxonomic names and misidentified specimens is a subjective task and should be further examined.

\section{Summary and Conclusions}

There were no differences in student performance, as a result of the type of web-based instruction received. One reason for failure to identify insects may be students' inability or unwillingness to carefully examine prepared specimens during sight identification. It is possible that many students, at least in the early weeks of insect identification courses, are unwilling to carefully examine specimens through magnification. This could be due to their fear of touching insects or because they are unfamiliar with the use of magnifying instruments. Future studies on insect identification should examine how students observe prepared specimens and examine morphological characteristics. Data gathered from this research may yield better methods in instructing students to visually observe morphological characteristics. Additional studies should then examine how these methods can best be utilized in both inclass and web-based instruction.

Another suggested method for improving student learning and knowledge retention in specimen identification includes incorporating simultaneous instruction in the insect's biology and ecological and environmental importance when learning to identify an organism (Day 2001). Perhaps, experiments that teach insect identification through the reinforcement of the insect's biology, ecological, and environmental importance can better help students learn insect identification. The result of using different instructional approaches, such as the inclusion of biological and ecological knowledge, should be investigated.

Additionally, all groups demonstrated improvements in pictorial specimen identification from webbased pre-quiz to post-quiz scores. Learning did occur as a result of the web-based tutorials. This indicates that even brief instruction through web pages may be an effective means of teaching insect identification. Further research in this area may help to more accurately reveal the amount of knowledge gained via web-based instruction, versus in-class instruction, and the methods necessary to best teach insect identification in online courses.

Results of this study also indicate that students performed better in identifying broader levels of classification (i.e., class level) versus more specific levels of classification (i.e., family level). Future studies examining specific reasons for the increased difficulty in identifying specimens to higher levels of classification may assist in revealing ways in which instruction can be modified to improve student performance. Additionally, studies examining the implications that position effect 
and gains in student expertise throughout the duration of a course have on student performance in identifying specimens may provide insight as the most effective order in which to present these groups to students.

Errorsinidentificationwereduemostly tomisidentification, versus spellingerrors, regardless of treatment group. While the true nature of these errors was confounded by the instructional treatment, the results suggest that misidentification is a greater cause of errors than students' inability to spell. Future results should examine errors without the confines of an instructional intervention.

In summary, it is hoped that this study provides a solid basis from which other studies can be developed, in an effort to improve the use of the World Wide Web for biological identification. This study is also more generally applicable to other areas of pedagogy examining the efficacy of web-based instruction and its impact on student performance.

\section{References}

Biederman, I. (1987). Recognition-by-components: a theory of human image understanding. Psychological Review 94: 115-147.

Biederman, I., and M.M. Shiffrar (1987). Sexing day old chicks: a case study and expert systems analysis of a difficult perceptual learning task. Journal of Experimental Psychology Learning Memory and Cognition 13(4): 640-645.

Blair, M. (2004). Error reduction and simplicity: opposing goals in classification learning. Proceedings of CogSci: 26, Chicago, Ill.

Borror, D.J., and R.E. White (1970). A Field Guide to the Insects of America North of Mexico. Houghton Mifflin, Boston.

Brooks, D.W., D.E. Nolan, and S.M. Gallagher (2001). Web-Teaching: A Guide to Designing Interactive Teaching for the World-Wide-Web, 2nd edition. Kluwer Academic, New York.

Day, R. (2001) What are we supposed to see? Visual perception of small aquatic animals by non-science majors and biology graduate students: comparisons and implications. Paper presented at the Annual International Conference of the Association for the Education of Teachers of Science. Costa Mesa, Calif. Retrieved 8/29/2004 from http://www.angelfire.com/ri/skibizniz/AETSsynopsis.htm.

Draper, B.A., B. Kyungim, and J. Boody (2004). Implementing the expert object recognition pathway. Machine vision and application. Retrieved 10/05/05 from http://www.cs.colostate.edu/*draper/ publications/draper_mva04.pdf.

Dunn, G.D. (1994). The Insect Identification Guide, 3rd edition. Young Entomologists Society, Lansing, Mich.

Goldstone, R.L. (1998). Perceptual learning. Annual Review of Psychology 49: 585-612.

Green, S.B., and N.J. Salkind (2010). Using SPSS for Windows and Macintosh: Analyzing and Understanding Data, 6th edition. Pearson Prentice Hall, Upper Saddle River, N.J.

Hai-Jew, S. (2011). The participatory design of a (today and) Future Digital Entomology Lab. EDUCAUSE Q 34(3). http://www.educause.edu/EDUCAUSE?Quarterly/EDUCAUSEQuarterlyMagazineVolum/TheParticipatoryDesignofaToday/236669.

Horsey, R. (2002). The art of chicken sexing. UCL Working Papers in Linguistics 14: 107-117.

Insectidentification.org. (2012). Retrieved from http://insectidentification.org.

Johnson, N.F., and C.A. Triplehorn (2005). Borror and Delong's Introduction to the Study of Insects, 7th edition. Brooks/Cole, Belomot, Calif.

Lin, E.L., and G.L. Murphy (1997). Effects on background knowledge on object categorization and part detection. Journal of Experimental Psychology: Human Perception and Performance 23(4): 1,153-1,169.
Little, T.M., and F. J. Hills (1978). Agricultural Experimentation: Design and Analysis. John Wiley and Sons, New York.

Markman, A.B., and D. Genter (2001). Thinking. Annual Review of Psychology 52: 223-247.

Markman, A.B., and B.H. Ross (2003). Category use and category learning. Psychological Bulletin 129(4): 592-613.

Marr, D. (1982). Vision: A Computational Investigation into the Human Representation and Processing of Visual Information. W.H. Freeman, San Francisco, Calif.

Medin, D.L., and M.M. Schaffer (1978). Context theory of classification. Psychological Review 85: 207-238.

Nosofsky, R.M. (1986). Attention, similarity, and the identificationcategorization relationship. Journal of Experimental Psychology: General 115(1): 39-57.

Nosofsky, R.M. (1987). Attention and learning process in the identification and categorization of integral stimuli. Journal of Experimental Psychology 13(1): 87-108.

Nosofsky, R.M., and S.R. Zaki (2002). Exemplar prototype models revisited: response strategies, selective attention, and stimulus generalization. Journal of Experimental Psychology Learning Memory and Cognition 28: 924-940.

Nosofsky, R.M., S.E. Clark, and H.J. Shin (1989). Rules and exemplars in categorization, identification, and recognition. Journal of Experimental Psychology Learning Memory and Cognition 15(2): 282-304.

Peters, R.J., F. Gabbiani, and C. Koch (2003). Human visual object categorization can be described by models with low memory capacity. Vision Research 43: 2,265-2,280.

Proffitt, J.B., J.D. Coley, and D.L. Medin (2000). Expertise in category-based induction. Journal of Experimental Psychology Learning Memory and Cognition 26(4): 811-828.

Pylyshyn, Z. (editor) (2003). Seeing and Visualizing: It's Not What You Think. MIT Press, Cambridge, Mass.

Risenhuber, M., and T. Poggio (2000). Models of object recognition. Nature Nueroscience Supplement 3: 1,199-1,203.

Rosch, E. (1978). Principles of categorization. In: E. Rosch (editor) Cognition and Categorization. L. Erlbaum, Hillsdale, N.J., pp 27-48.

Sakamoto, Y., and B.C. Love (2003). Category structure and recognition memory. In: R. Alterman and D. Kirsh (editors) CogSci: 25. The Social, Cultural, and Contextual Elements of Cognition. Northwestern University, Chicago.

Schyns, P.G. (1998). Diagnostic recognition: task constraints, object information, and their interactions. In: M.J. Tarr and H.H. Bulthoff (editors) Object Recognition in Man, Monkey, and Machine. MIT Press, Cambridge, Mass., pp. 147-179.

Shafto, P., and J.D. Coley (2003). Development of categorization and reasoning in the natural world: novice to experts, naïve similarity to ecological knowledge. Journal of Experimental Psychology Learning Memory and Cognition 29(4): 641-649.

Stanley,E.,D.Whitman, andD.Rhodes(1996).InvestigatingInsectOrders. Retrieved from http://www.bioquest.org/EStanley/insects.html.

Tabachnick, B.G., and L.S. Fidell (2001). Computer-Assisted Research Design and Analysis. Allyn \& Bacon, Needham Heights, Mass.

Tarr, M.J. (2003). Visual object recognition: can a single mechanism suffice? In: M.A. Peterson and G. Rhodes (editors) Perception of Face, Objects, and Scenes: Analytic and Holistic Processes. Oxford University Press, Oxford, U.K.

Tarr, M.J., and H.H. Bulthoff (1998) Image-based object recognition in man, monkey, and machine. In: M.J. Tarr and H.H. Bulthoff (editors) Object Recognition in Man, Monkey, and Machine. MIT Press, Cambridge, Mass., pp. 1-20.

Turpin, F.T. (1997) The Insect Appreciation Digest: Everything You Ought to Know about Insects (That Your Parents Didn't Teach You). Entomological Foundation, Lanham, Md.

Ullman, S. (1998) Three-dimensional object recognition based on a combination of views. In: M.J. Tarr and H.H. Bulthoff (editors) Object Recognition in Man, Monkey, and Machine. MIT Press, Cambridge, Mass., pp. 1-20.

Yamauchi, T., and A.B. Markman (1998). Category learning by inference and classification. Journal of Memory and Language 39: 124-148. 